Ewelina Woźnicka ${ }^{1}$

ORIGINAL PAPER

Ewa Niebudek-Bogusz ${ }^{1}$

Joanna Morawska ${ }^{1}$

Justyna Wiktorowicz ${ }^{2}$

Mariola Śliwińska-Kowalska ${ }^{1}$

\title{
LARYNGEAL MANUAL THERAPY PALPATORY EVALUATION SCALE: A PRELIMINARY STUDY TO EXAMINE ITS USEFULNESS IN DIAGNOSIS OF OCCUPATIONAL DYSPHONIA
}

\author{
${ }^{1}$ Nofer Institute of Occupational Medicine, Łódź, Poland \\ Audiology and Phoniatrics Clinic \\ ${ }^{2}$ University of Lodz, Łódź, Poland \\ Department of Economic and Social Statistics
}

\begin{abstract}
Background: The aim of this study has been to assess the larynx and soft tissue around the vocal tract in a group of people with healthy voice, and in a group of patients with occupational dysphonia using the new laryngeal manual therapy palpatory evaluation scale (LMTPE). Material and Methods: The examinations were performed in a study (dysphonic) group of professional voice users who had developed voice disorders $(\mathrm{N}=51)$ and in the control group of normophonic subjects $(\mathrm{N}=50)$. All the participants underwent perceptual voice assessment and examination by means of the LMTPE scale. Additionally, phoniatric examination including VHI (Voice Handicap Index) questionnaire, GRBAS (the Grade of hoarseness, Roughness, Breathiness, Asthenic, Strained) perceptual evaluation, maximum phonation time (MPT) measurement and videostroboscopy was performed in the study group. Results: The comparison of the LMTPE total score showed that the results of the study group were significantly poorer than those of controls $(\mathrm{p}<0.001)$. In the study group, correlations were found between the LMTPE results and the VHI scores $(\mathrm{p}<0.05)$, perceptual evaluation by the GRBAS $(\mathrm{p}<0.05)$ and the objective parameter MPT $(\mathrm{p}<0.05)$. Conclusions: The study has proven that the LMTPE scale is characterized by the high score of Cronbach's a ratio estimating the reliability of the test. The results have confirmed that the LMTPE scale seems to be a valuable tool, useful in diagnostics of occupational dysphonia, particularly of hyperfunction origin. Med Pr 2017;68(2):179-188
\end{abstract}

Key words: assessment, occupational voice disorders, palpation, larynx, laryngeal manual therapy palpatory evaluation scale, laryngeal muscle tension

Corresponding author: Ewelina Woźnicka, Nofer Institute of Occupational Medicine, Audiology and Phoniatrics Clinic, św. Teresy 8, 91-348 Łódź, Poland, e-mail: ewelina.woznicka@imp.lodz.pl Received: February 5, 2016, accepted: January 10, 2017

\section{INTRODUCTION}

Voice disorders usually affect professional voice users. It is a fact acknowledged by most clinicians and authors that teachers are the largest professional group diagnosed with voice problems [1-3]. The etiological factors responsible for these disorders include: prolonged use of voice, excessive loading of the voice organ, non-optimum phonation technique, failure to comply with the principles of hygiene and work in unsuitable climatic conditions $[4,5]$. It is increasingly believed that psychogenic factors may also be involved in the development of voice disorders [6,7]. Kooijman et al. [8] have conclu- ded that stressful situations typically cause tension in the muscles of neck and lumbar spine, but professional voice users additionally tend to transfer the tension onto the internal and external muscles of the larynx and pharynx.

Similarly, Nichol et al. [9] have observed that the symptoms of tension result from hyperactivity of the autonomic and peripheral nervous system, which is typical for people with high levels of anxiety and hyperactive individuals. Interestingly, such hyperactivity may lead to symptoms of hyperfunctional dysphonia, typical for the first stage of occupational voice disorders. If left untreated, these symptoms may progress to organic changes in the form of vocal nodules.

Funding: part of this study was supported by the project of the Polish State Committee for Scientific Research. Project No. 18.1/12, entitled "Applicability of laryngeal manual therapy in rehabilitation of functional voice disorders." Project manager: Ewelina Woźnicka, Ph.D. 
According to many clinicians, most people with work-related hyperfunctional dysphonia are diagnosed with voice fatigue syndrome resulting from improper compensation of vocal loading $[10,11]$. Discomfort experienced by patients, sometimes even tenderness and pain within the perilaryngeal structures prevent the production of voice. Prolonged, untreated dysphonia results in problems with the neuromuscular apparatus of the larynx, increased tension of masseter, buccal fundus, and suprahyoid muscles, which excessively raises the position of the larynx $[12,13]$. The tension induces lack of coordination between breathing, phonation and articulation, and adversely affects the quality and efficiency of voice.

Occupation-related voice disorders require a comprehensive diagnosis, including palpation to evaluate disorders and dysfunctions within the vocal tract. Currently, there are few standardized methods for assessing perilaryngeal muscles. The Jacob Lieberman protocol used by physiotherapists/osteopaths is an example of methods used most frequently in Poland [14]. Mathieson et al. [15] have proposed a new simple system for assessing tension of individual vocal tract structures, the Laryngeal Manual Therapy Palpatory Evaluation (LMTPE) scale. In their monograph the authors stress the importance of the scale in the diagnosis and monitoring of therapy of functional voice disorders. Therefore, the aim of the study has been to evaluate the applicability of the Polish version of the LMTPE scale in the diagnosis of occupational dysphonia.

\section{MATERIAL AND METHODS}

The study was conducted in a group of 51 female professional voice users who had developed voice disorders and who were diagnosed by a phoniatrician in the Department of Audiology and Phoniatrics Clinic of the Nofer Institute of Occupational Medicine in Łódź. The average age of the study population was 44 years old. The control group consisted of 50 women with euphonic voice. The controls were not professional voice users, did not smoke, did not report any prior or current vocal problems. The average age was 42 years old (Table 1).

Assessment of the larynx and the soft tissues around the vocal tract was performed for all 101 participants of the study using the Polish version of the LMTPE scale. The assessment included:

1. Sternocleidomastoid muscle right (SCM right).

2. Sternocleidomastoid muscle left (SCM left).

3. Supralaryngeal area.

4. Laryngeal resistance to lateral pressure.

Perilaryngeal muscle tension is assessed in the range $0-5$, where 0 represents the minimum resistance, and 5 denotes the maximum resistance. The second section of the scale determines the position of the larynx, which can be:

A. Elevated.

B. Neutral.

C. Low.

D. Very low.

Total score of the "tension" subscale may range $0-20$ points. Palpatory evaluation of the perilaryngeal musculature was carried out by the first author who had held a certificate of the Laryngeal Manual Therapy course led by Mathieson in the Royal Society of Medicine in London. She had prior experience of 6 years working full time in a specialized voice clinic, treating patients with occupational voice disorders.

The subjects from both groups also completed the Voice Handicap Index (VHI) questionnaire which was a well known and widely used self-rating test evaluating the biopsychosocial impact of voice problems [16]. It examines the impact of voice disorders in 3 domains of life: functional (VHI-F), emotional (VHI-E) and physical (VHI-P). The result obtained within the limit $0-30$ is defined as a minor voice handicap, $31-60$ is

Table 1. Characteristics of the study group (professional voice users who developed voice disorders) and the control group (not professional voice users with euphonic voice) in the study of perceptual voice assessment

\begin{tabular}{|c|c|c|c|}
\hline \multirow{3}{*}{ Groups } & \multicolumn{3}{|c|}{ Respondents } \\
\hline & \multicolumn{2}{|c|}{$\begin{array}{c}\text { age } \\
\text { [years] }\end{array}$} & \multirow{2}{*}{$\begin{array}{l}\text { employment duration } \\
\text { [years] } \\
(\mathrm{M})\end{array}$} \\
\hline & M & $\min .-\max$ & \\
\hline Study group $(\mathrm{N}=51)$ & 42.0 & $26-55$ & 17.7 \\
\hline A) respondents with vocal nodules $(\mathrm{N}=16)$ & 41.4 & $27-55$ & 17.5 \\
\hline
\end{tabular}


an average voice handicap, and the result of 61-120 points indicates a serious voice handicap.

Moreover, all patients had their voice perceptually assessed with the use of the GRBAS scale. This scale, developed by the Japanese Society of Logopedics and Phoniatrics, describes voice disorders with 5 well-defined parameters: G (grade of hoarseness), R (roughness), B (breathiness), A (asthenic), S (strained). The scale has 4 levels of disorders, intensity in which " 0 " means normal, " 1 " slightly disordered, " 2 " - moderately disordered, “ 3 " severely disordered, with respect to all para meters.

A phoniatrician and 2 speech and voice therapists who specialized in the assessment and treatment of people with voice disorders were recruited as judges. They had more than 10 years of experience and were familiar with the GRBAS scale. The perceptual voice evaluation included automatic speech (counting from 1-10 and listing the days of the week), prolonged vowels /i/ and /a/ between 3 and $5 \mathrm{~s}$. (with comfortable pitch and loudness) and spontaneous speech upon the request "Tell me about your voice." These voice samples represent routine clinical material for the evaluation of voice quality. The results were subject to calculation of the mean value for 3 assessments.

Voice assessment in the study (dysphonic) group also involved measurement of maximum phonation time (MPT). The MPT was measured in the following way: the subject was asked to phonate a sustained /a:/ vowel at a comfortable pitch and loudness as long as possible during a single exhalation. The result of the MPT is an average of three consecutive measurements and its decrease below $10 \mathrm{~s}$ (i.e., the minimum normal MPT value) usually indicates voice disorders.

Additionally, in the study group phoniatric examination including videostroboscopy was performed.

\section{Statistical methods}

The SPSS software package (version 22.0) was used for the statistical analyses purposes. The comparison of the total score of the muscle tension and resistance in the perilaryngeal musculature evaluated in the LMTPE scale between the study group and the control group was performed by means of the Student's t-test and the comparison of the tension in the individual tissues - by means of the Student's t-test. The value equivalent to $\mathrm{p} \leq 0.05$ was considered to be at the level of significance.

Mann-Whitney $U$ test was used for comparing the position of the larynx in the 2 groups. In addition, the tissue tension and the position of the larynx were compared in 2 subgroups of patients: with vocal nodules and with hyperfunctional dysphonia using the MannWhitney U test.

The analysis of the relationship between the results of the MPT measurement, the VHI questionnaire, the GRBAS scale and LMTPE was carried out using Spearman's rank correlation coefficient. The reliability of the constructed Polish LMTPE scale was assessed by means of Cronbach's a reliability coefficient, which describes the extent to which all the items in a test measure the same concept or construct, and hence it is connected to the inter-relatedness of the items within the test.

\section{RESULTS}

Based on the results of phoniatric and videostroboscopic examinations and diagnosis, the subjects of the study group with occupational dysphonia were classified into the following subgroups: vocal nodules (31.4\%) and hyperfunctional dysphonia (68.6\%) (Table 1).

Comparison of average overall assessment of perilaryngeal tissue tension by the LMTPE scale in the study and the control group was carried out. The statistical analysis of the overall tension results demonstrated a statistically significant difference between the patients and the controls $(\mathrm{p}<0.001)$. The result of tissue tension in the study group was 12 points and it was significantly higher than for the control group, in which the result was 0.56 point (Figure 1).

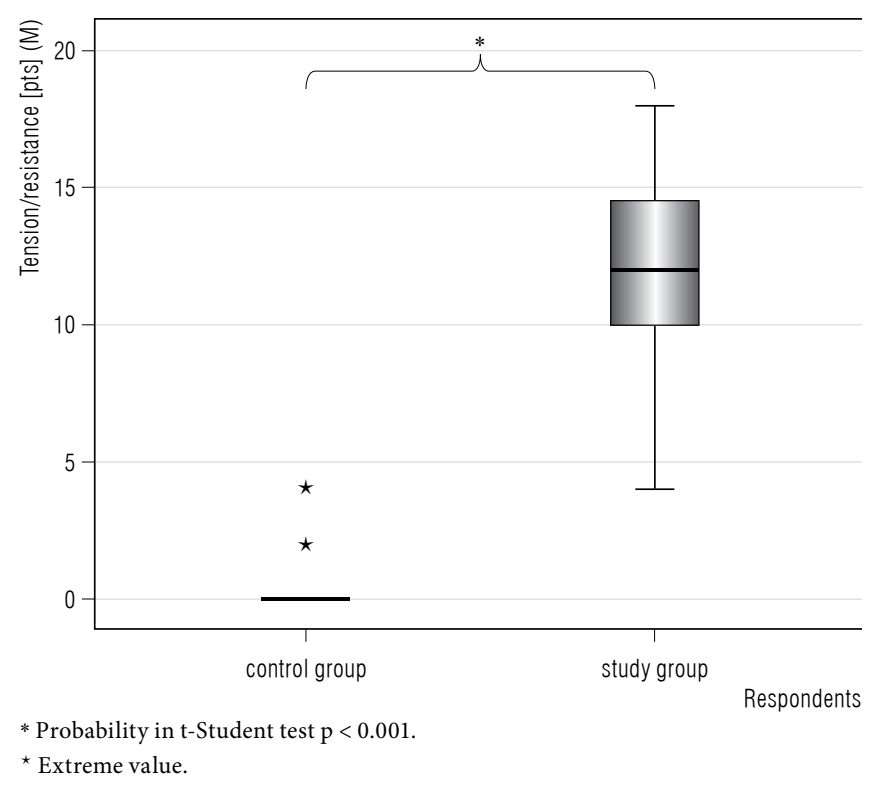

Fig. 1. Average overall assessment of perilaryngeal muscle tension by laryngeal manual therapy palpatory evaluation (LMTPE) scale in the control and study group 
The position of the larynx in both groups was also compared (Figure 2). As an ordinal scale, the LMTPE cannot express the results in the form of arithmetic mean values $(\mathrm{M})$. Therefore, the calculation of median values was performed to indicate central trends characterizing the distribution of measurement results. Mann-Whitney $U$ test was used for this purpose, and it showed a statistically significant difference between the groups ( $<<0.001)$. The median for the control group was 2 , and for the study group it was 1 , which confirms

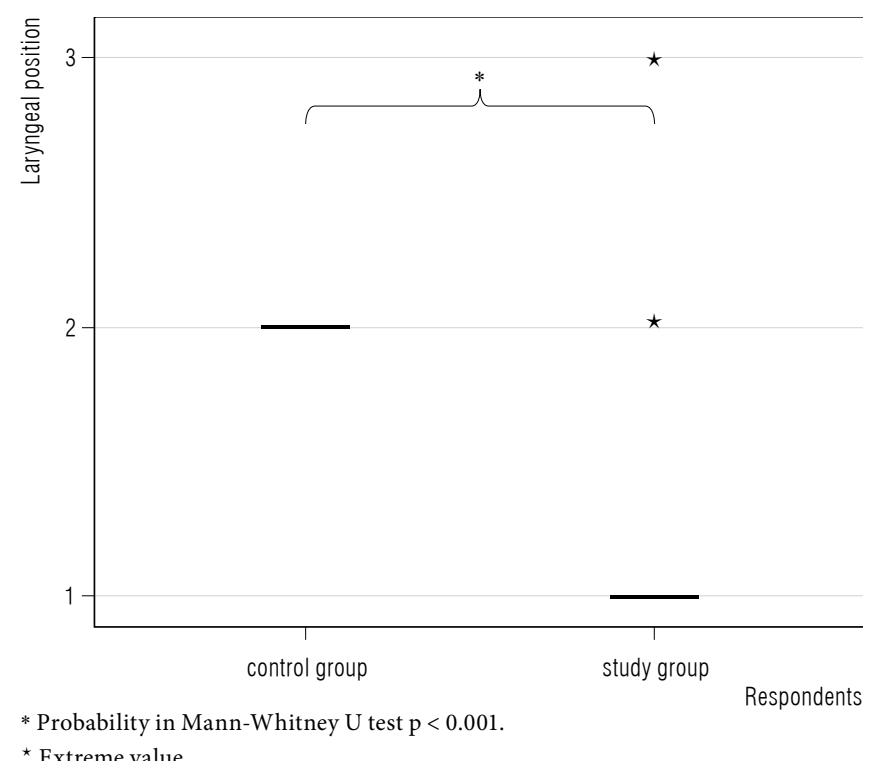

Fig. 2. Laryngeal position assessed by laryngeal manual therapy palpatory evaluation (LMTPE) scale in the control and study group the neutral position of the larynx in the control group, as opposed to its elevated position in the study group.

The Figure 3 shows the comparison of the average scores for each of tension subscale items in both groups. Statistically significant differences for all the analyzed LMTPE scale items were confirmed by the t-test. The analysis of the values of the "tension" subscale revealed the mean value in the control group, that equaled 0.14 , while the corresponding value for the study group was above $3(\mathrm{p}<0.001)$.

The research showed poorer results obtained both in the "tension" and the "laryngeal position" subscale for patients with voice disorders as compared with the control group.

Mean values of individual structures of tension measured by the LMTPE scale between disorder-based subgroups were then compared. It should be noted that both in the subgroup with vocal nodules (A) and the subgroup with hyperfunctional dysphonia (B), the mean tension in the perilaryngeal structures was the same and equal to 12 (Figure 4). Comparable results were observed in assessing the laryngeal position; median value for both subgroups was 1 , which confirms that the position of the larynx in both groups was abnormal, i.e., elevated (Figure 5).

In the next stage of the study we analyzed the results of the Voice Handicap Index and the maximum phonation time in the study group. The average total score of the VHI was 45.88. The highest value was recorded in the physical subscale ( $M=21$ points); followed by

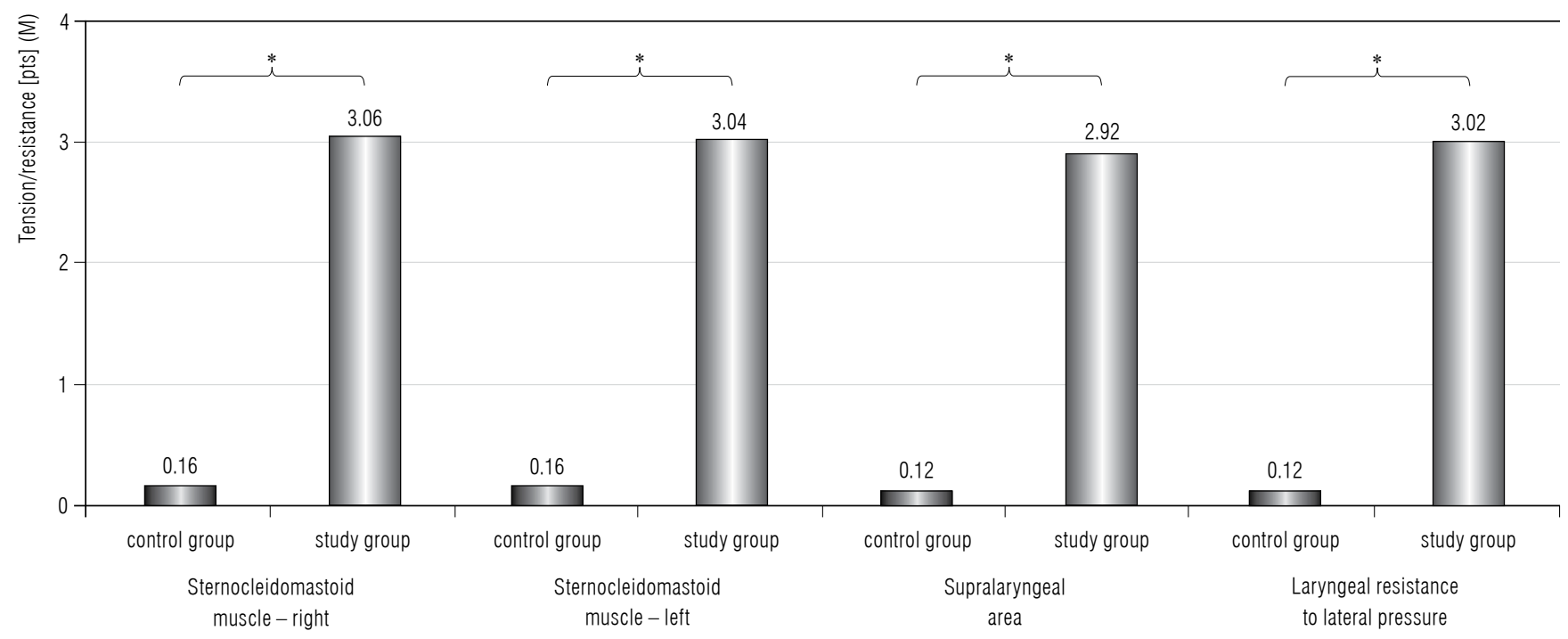

* Probability in t-Student test $\mathrm{p}<0.001$.

Fig. 3. Average results of the individual items of the laryngeal manual therapy palpatory evaluation (LMTPE) tension subscale in the control and study group 


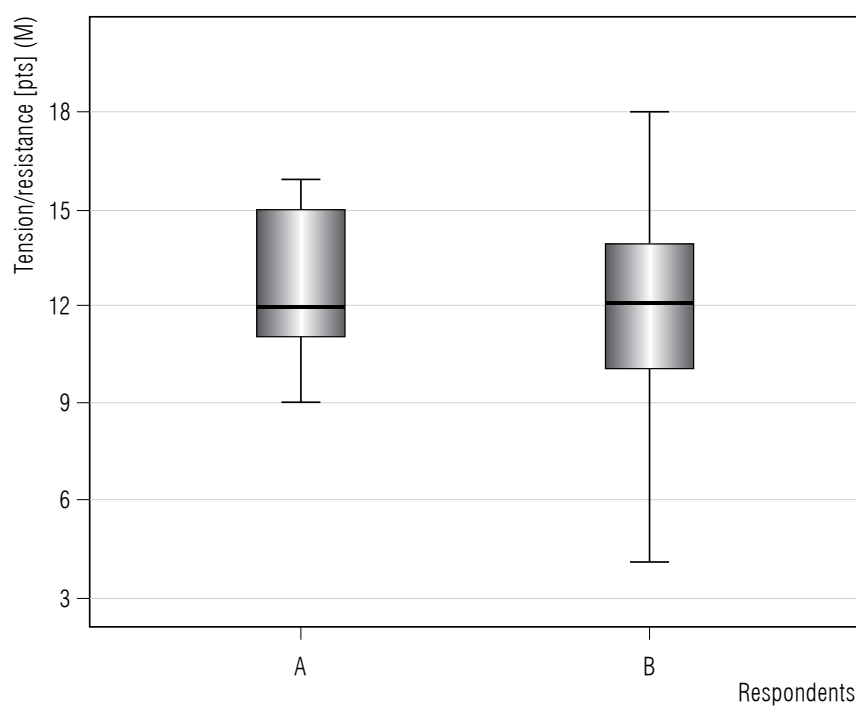

Fig. 4. Comparison of box plots of the average results of the perilaryngeal muscle tension in the respective subgroups of patients: A) with vocal nodules and B) with hyperfunctional dysphonia

the emotional subscale ( $\mathrm{M}=14$ points) and with the lowest in the functional subscale ( $\mathrm{M}=11.3$ points). The average maximum phonation time was considerably reduced, shorter than $11 \mathrm{~s}$, which indicates diminished efficiency of the vocal tract.

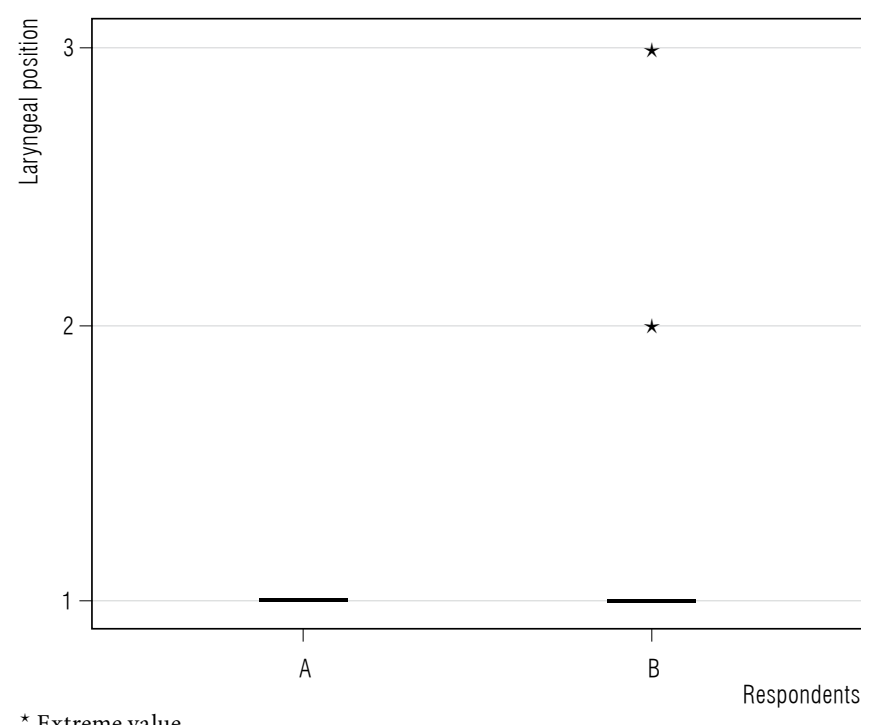

* Extreme value.

Fig. 5. Comparison of box plots of the average results of laryngeal position in the respective subgroups of patients: A) with vocal nodules and $\mathrm{B}$ ) with hyperfunctional dysphonia

In addition, the results of the LMTPE scale correlated significantly $(\mathrm{p}<0.05)$ both with maximum phonation time and with the VHI results (total and subscales) (Table 2). For the correlation relationship between all items of the LMTPE subscale "tension" and

Table 2. Correlation between the laryngeal manual therapy palpatory evaluation (LMTPE) results and Voice Handicap Index (VHI) score and maximum phonation time (MPT)

\begin{tabular}{|c|c|c|c|c|c|}
\hline \multirow{2}{*}{ LMTPE scale } & \multirow{2}{*}{ MPT } & \multicolumn{4}{|c|}{ VHI } \\
\hline & & functional & emotional & physical & total \\
\hline \multicolumn{6}{|l|}{$\begin{array}{l}\text { Sternocleidomastoid muscle } \\
\text { right }\end{array}$} \\
\hline rho & -0.357 & 0.390 & 0.404 & $0.312^{\star}$ & 0.361 \\
\hline $\mathrm{p}$ & $0.010^{*}$ & $0.005^{\star}$ & $0.003^{*}$ & $0.026^{*}$ & $0.009^{*}$ \\
\hline \multicolumn{6}{|l|}{ left } \\
\hline $\mathrm{p}$ & $0.020^{*}$ & $0.002^{*}$ & $0.001^{*}$ & $0.011^{*}$ & $0.004^{*}$ \\
\hline \multicolumn{6}{|l|}{ Supralaryngeal area } \\
\hline rho & -0.289 & 0.389 & 0.396 & 0.364 & 0.421 \\
\hline $\mathrm{p}$ & $0.040^{*}$ & $0.005^{\star}$ & $0.004^{\star}$ & $0.009^{*}$ & $0.002^{*}$ \\
\hline \multicolumn{6}{|c|}{ Laryngeal resistance to lateral pressure } \\
\hline rho & -0.104 & 0.017 & 0.000 & 0.071 & 0.058 \\
\hline $\mathrm{p}$ & 0.469 & 0.908 & 1.000 & 0.623 & 0.684 \\
\hline \multicolumn{6}{|l|}{ LMTPE (total) } \\
\hline rho & -0.343 & 0.487 & 0.454 & 0.390 & 0.470 \\
\hline $\mathrm{p}$ & $0.014^{*}$ & $0.001^{*}$ & $0.001^{*}$ & $0.005^{*}$ & $0.001^{\star}$ \\
\hline
\end{tabular}

rho - Spearman's rank correlation coefficient.

${ }^{*} \mathrm{p}<0.05$. 
maximum phonation time - the correlation coefficient was negative $(p=0.014$, rho $=-0.343)$. It means that the relationship was inversely proportional, i.e., the aerodynamic parameter (MPT) decreased with increasing laryngeal tension.

On the other hand, positive correlation was observed for the overall results of the LMTPE scale and both the total VHI result and each of its subscales (Table 2). The overall result of the LMTPE scale level of significance was $\mathrm{p}=0.001$ ( $\mathrm{rho}=0.470$ ) for the relationship with the VHI total, $\mathrm{p}=0.001$ ( $\mathrm{rho}=0.487$ ) for the VHI functional subscale, $\mathrm{p}=0.001(\mathrm{rho}=0.454)$ for the emotional subscale, $\mathrm{p}=0.001(\mathrm{rho}=0.390)$ for the physical subscale. Moreover, the strongest correlation was observed for the items of the "tissue tension" subscale with functional, emotional and physical VHI subscales $(\mathrm{p}<0.05)$. Additionally, very strong correlation was observed for all items of the "tension" subscale with functional, emotional and physical VHI subscales, which points to a strong relationship between these items (Table 3).

The analysis of the relationship between the results for each LMTPE subscale and perceptual evaluation of voice revealed the statistically significant correlation for 3 parameters of the GRBAS scale: "G" - grade of hoarseness $(p=0.006$, rho $=0.379)$, " $R$ " - roughness of voice $(\mathrm{p}=0.030$, rho $=0.305)$ and " $\mathrm{S}$ " - strained voice $(\mathrm{p}=0.001$, rho $=0.584)$ and the tension of individual tissues. Moreover, a correlation was observed for the "laryngeal position" subscale and the parameter "A" asthenic voice $(\mathrm{p}=0.046$, rho $=0.281)$ (Table 4$)$.

The next stage of the study assessed the reliability of the Polish LMTPE scale in terms of basic psychometric properties using Cronbach's a test. This coefficient was 0.971 and 0.922 in the control group and study group respectively, indicating a high reliability of the developed Polish LMTPE scale.

\section{DISCUSSION}

The review of literature shows that patients with dysphonia experience increased muscle tension outside the larynx, which changes its position in relation to other structures of the vocal tract and consequently disrupts the conditions of voice emission $[17,18]$. The transfer of myofascial tension from the area of the neck, jaw to the deeper structures i.e., inner muscles of the larynx has been signaled by many authors $[19,20]$. Due to this fact, as reported by Mathieson et al. [15], palpatory assessment of the tension of individual anatomical elements

Table 3. Correlation between "tension" and "laryngeal position" subscales of laryngeal manual therapy palpatory evaluation (LMTPE) scale

\begin{tabular}{|c|c|c|c|c|c|}
\hline \multirow{2}{*}{ LMTPE scale } & \multicolumn{2}{|c|}{ Sternocleidomastoid muscle } & \multirow{2}{*}{$\begin{array}{c}\text { Supralaryngeal } \\
\text { area }\end{array}$} & \multirow{2}{*}{$\begin{array}{c}\text { Laryngeal } \\
\text { resistance } \\
\text { to lateral pressure }\end{array}$} & \multirow{2}{*}{ Laryngeal position } \\
\hline & right & left & & & \\
\hline \multicolumn{6}{|l|}{ Sternocleidomastoid muscle } \\
\hline \multicolumn{6}{|l|}{ right } \\
\hline rho & 1.000 & 0.998 & 0.934 & 0.942 & -0.668 \\
\hline $\mathrm{p}$ & - & $0.001^{*}$ & $0.001^{*}$ & $0.001^{*}$ & $0.001^{*}$ \\
\hline \multicolumn{6}{|l|}{ left } \\
\hline rho & 0.998 & 1.000 & 0.939 & 0.944 & -0.667 \\
\hline $\mathrm{p}$ & $0.001^{*}$ & - & $0.001^{*}$ & $0.001^{*}$ & $0.001^{*}$ \\
\hline \multicolumn{6}{|l|}{ Supralaryngeal area } \\
\hline rho & 0.934 & 0.939 & 1.000 & 0.950 & -0.666 \\
\hline $\mathrm{p}$ & $0.001^{\star}$ & $0.001^{\star}$ & - & $0.001^{\star}$ & $0.001^{*}$ \\
\hline \multicolumn{6}{|c|}{ Laryngeal resistance to lateral pressure } \\
\hline rho & 0.942 & 0.944 & 0.950 & 1.000 & -0.621 \\
\hline $\mathrm{p}$ & $0.001^{\star}$ & $0.001^{\star}$ & $0.001^{*}$ & - & $0.001^{\star}$ \\
\hline \multicolumn{6}{|l|}{ Laryngeal position } \\
\hline rho & -0.668 & -0.667 & -0.666 & -0.621 & 1.000 \\
\hline $\mathrm{p}$ & $0.001^{*}$ & $0.001^{*}$ & $0.001^{*}$ & $0.001^{*}$ & - \\
\hline
\end{tabular}


Table 4. Correlation between GRBAS and laryngeal manual therapy palpatory evaluation (LMTPE) scale

\begin{tabular}{|c|c|c|c|c|c|}
\hline LMTPE scale & G & $\mathrm{R}$ & B & A & $S$ \\
\hline \multicolumn{6}{|l|}{ right } \\
\hline rho & 0.372 & 0.228 & 0.116 & 0.148 & 0.600 \\
\hline $\mathrm{p}$ & $0.007^{*}$ & 0.107 & 0.418 & 0.301 & $0.001^{\star}$ \\
\hline $\mathrm{p}$ & $0.008^{*}$ & 0.059 & 0.353 & 0.250 & $0.001^{\star}$ \\
\hline \multicolumn{6}{|l|}{ Supralaryngeal area } \\
\hline rho & 0.327 & 0.192 & 0.182 & 0.146 & 0.443 \\
\hline $\mathrm{p}$ & $0.019^{*}$ & 0.178 & 0.202 & 0.305 & $0.001^{\star}$ \\
\hline $\mathrm{p}$ & $0.012^{\star}$ & $0.022^{*}$ & 0.106 & 0.258 & $0.001^{\star}$ \\
\hline \multicolumn{6}{|l|}{ Laryngeal position } \\
\hline rho & -0.238 & -0.139 & 0.215 & 0.281 & -0.088 \\
\hline $\mathrm{p}$ & 0.092 & 0.330 & 0.130 & $0.046^{*}$ & 0.541 \\
\hline \multicolumn{6}{|l|}{ LMTPE (total) } \\
\hline rho & 0.379 & 0.305 & 0.195 & 0.179 & 0.584 \\
\hline $\mathrm{p}$ & $0.006^{*}$ & $0.030^{*}$ & 0.171 & 0.210 & $0.001^{*}$ \\
\hline
\end{tabular}

GRBAS $=\mathrm{G}$ - grade of hoarseness, $\mathrm{R}$ - roughness, $\mathrm{B}$ - breathiness, $\mathrm{A}$ - asthenic, $\mathrm{S}-$ strained.

Other abbreviations as in Table 2.

having a direct or indirect impact on the function and position of the larynx is important in the diagnosis. For this reason, the aim of this study has been to evaluate the use of the Polish version of the LMTPE scale in detecting voice disorders. The research using that scale was conducted for patients with diagnosed occupational voice disorders, and for patients with euphonic voice.

While comparing the average overall score of perilaryngeal tissue tension in the LMTPE scale it was found that teachers from the dysphonic group showed significantly poorer results as compared to the control group ( $<0.01)$. Similarly, for all items of the "tension" subscale, there was a significant difference between groups ( $p=0.000$ ), i.e., sternocleidomastoid, supralaryngeal muscles, and larynx resistance to lateral pressure.

Significant differences between the control group of normophonic subjects and the group of teachers with occupational dysphonia were recorded also in the "laryngeal position" subscale $(\mathrm{p}=0.000)$. It indicates an elevated position of the larynx in professional voice users, one of the most common symptoms of hyperfunctional dysphonia.
Besides, our results have shown correlations between results of the "tension" and the "laryngeal position" subscales. These results are in accordance with similar studies (for example by Aronson et al. and others $[20,21])$ and confirm that increased laryngeal tension may trigger improper, elevated positioning of the larynx, and additionally cause muscle pain reactions in the neck and throat. The role of hyperfunction of neck muscles in the etiology of voice disorders was studied by Roy et al. [22] who reported that excessive muscle tension in the larynx raised it toward the hyoid bone, which in turn adversely affected vocal quality and efficiency. These observations were confirmed by this research of ours.

The next step of our study was to determine the validity of the LMTPE scale. In order to do so, the relation between the results of the LMTPE scale and the VHI test was evaluated. The Voice Handicap Index (VHI) is currently the most widely used voice selfassessment test used for measuring vocal disability. A statistically significant correlation has been observed between the overall results of the LMTPE scale and 
those of the VHI questionnaire. Observations described above are reflected in clinical practice, as people in the study group reported reduced voice-related quality of life in direct proportion to the increase in the severity of laryngeal tension. The conducted research is in accordance with the studies carried out in other institutions and indicates that apart from the self-reported physical discomfort within the vocal tract, the patients also experience a wide range of problems of psychosocial nature $[23,24]$.

Furthermore, our studies have confirmed the correlation of the LMTPE scale results with the results obtained by means of methods commonly used in phoniatric practice, i.e., the aerodynamic parameter (MPT) and perceptual evaluation by the GRBAS.

There is little research on the validity and reliability of palpation methods. However, Kooijman et al. [8] reported high correlation of the results of Lieberman palpatory method and the Voice Handicap Index score. Additionally, Redenbaugh and Reich [25] presented moderately high correlations between palpation and sEMG (surface electromyography). Similarly, in our study a direct positive relationship has been demonstrated between results of the LMTPE scale and the VHI questionnaire, perceptual voice assessment (GRBAS scale) and objective parameters of maximum phonation time. This fact is of particular importance given that according to the Committee on Phoniatrics of the European Laryngological Society these three independent methods represent equivalent tests included in a battery of diagnostic tools [26].

In our study, we have also assessed the reliability of the LMTPE scale by Cronbach's a test, which is one of the methods extensively used for the evaluation of subjective scales. Literature data confirms the feasibility of that tool for analyzing the reliability and validity of the new-developed subjective scales [27,28]. The high reliability of the LMTPE scale has been confirmed by the values of Cronbach's a coefficient - in the control group this coefficient was 0.965 , and in the study group it was 0.934 . The high value of this coefficient means that the measurements of tension in the individual structures of the vocal tract are sufficiently precise and provide consistent and reproducible results.

In conclusion, our study confirms the findings of other clinicians that the presence of elevated tension of the soft tissues and abnormal movements of individual anatomical structures of the vocal tract is characteristic of professional dysphonia, especially on the hyperfunctional ground $[29,30]$. The assessment of direct manual examination by means of the LMTPE scale may play an important role in the early diagnosis of dysphonia, as well as facilitate the choice of a suitable manual therapy technique. Therefore, the authors firmly believe that this scale could be used in daily phoniatrics and speech therapy practice. Moreover, in the future it could also be applied to evaluate the effectiveness of voice therapy in voice disorders of hyperfunctional origin. However, this requires further research on a larger population.

\section{CONCLUSIONS}

1. The results show that perilaryngeal muscle tension and position of the larynx measured using the LMTPE scale is significantly higher in the group of patients with occupational voice disorders compared to normophonic people.

2. The Polish LMTPE scale is characterized by the high reliability and accuracy in terms of assessing perilaryngeal muscle tension and the position of the larynx.

3. The results of this scale correlate with other parameters of voice assessment used in the comprehensive diagnosis.

4. The LMTPE scale seems to be a valuable tool, useful in the diagnosis of occupational voice disorders.

\section{REFERENCES}

1. Marques da Rocha L, Behlau M, Dias de Mattos Souza L. Behavioral dysphonia and depression in elementary school teachers. J Voice. 2015;29(6):712-7, https://doi.org/10.10 16/j.jvoice.2014.10.011.

2. Sliwinska-Kowalska M, Niebudek-Bogusz E, Fiszer M, LosSpychalska T, Kotylo P, Sznurowska-Przygocka B, et al. The prevalence and risk factors for occupational voice disorders in teachers. Folia Phoniatr Logop. 2006;58(2):85-102, https://doi.org/10.1159/000089610.

3. Ziegler A, Gillespie A, Verdolini K. Behavioral treatment of voice disorders in teachers. Folia Phoniatr Logop. 2010; 62:9-23, https://doi.org/10.1159/000239059.

4. Obrebowski A. [The voice organ and its role in social communication]. 1st ed. Poznań: Medical University; 2008. Polish.

5. Calcinoni O, Niebudek-Bogusz E. Occupational voice. In: Rubin J, Sataloff R, Korovin G, editors. Diagnosis and treatment of voice disorders. 4th ed. San Diego: Plural Publishing; 2014. p. 735-62.

6. Kooijman P, Thomas G, Graamans K, de Jong F. Psychosocial impact of the teacher's voice throughout the career. 
J Voice. 2007;21(3):316-24, https://doi.org/10.1016/j.jvoice. 2005.12.007.

7. Jong F. An introduction to the teacher's voice in a biopsychosocial perspective. Folia Phoniatr Logop. 2010;62(1-2): 5-8, https://doi.org/10.1159/000239058.

8. Kooijman PGC, de Jong FICRS, Oudes MJ, Huinck W, van Acht W, Graamans K. Muscular tension and body posture in relation to voice handicap and voice quality in teachers with persistent voice complaints. Folia Phoniatr Logop. 2005;57:134-47, https://doi.org/10.1159/000084134.

9. Nichol H, Morrison M, Rammage L. Interdisciplinary approach to functional voice disorders: The psychiatrist's role. Otolaryngol Head Neck Surg. 1993;108:643-47, https:// doi.org/10.1177/019459989310800604.

10. Koufman JA, Blalock PD. Classification and approach to patients with functional voice disorders. Ann Otol Rhinol Laryngol. 1982;91:372-7, https://doi.org/10.1177/00 0348948209100409.

11. Belafsky PC, Postma G, Reulbach TR, Holland BW, Koufman JA. Muscle tension dysphonia as a sign of underlying glottal insufficiency. Otolaryngol Head Neck Surg. 2002;127(5):448-51, https://doi.org/10.1067/mhn. 2002.128894.

12. Altman KW, Atkinson C, Lazarus C. Current and emerging concepts in muscle tension dysphonia: A 30-month review. J Voice. 2005;19:261-7, https://doi.org/10.1016/ j.jvoice.2004.03.007.

13. Angsuwarangsee T, Morrison M. Extrinsic laryngeal muscular tension in patients with voice disorders. J Voice. 2002;16:333-43, https://doi.org/10.1016/S0892-1997(02) 00105-4.

14. Marszałek S, Niebudek-Bogusz E, Woźnicka E, Malińska J, Golusiński W, Śliwińska-Kowalska M. Assessment of the influence of osteopathic myofascial techniques on normalization of the vocal tract functions in patients with occupational dysphonia. Int J Occup Med Environ Health. 2012;25(3):225-35, https://doi.org/10.2478/s13382-0120041-7.

15. Mathieson L, Hirani SP, Epstein R, Baken RJ, Wood G, Rubin JS. Laryngeal manual therapy: A preliminary study to examine its treatment effects in the management of muscle tension dysphonia. J Voice. 2009;23(3):353-66, https:// doi.org/10.1016/j.jvoice.2007.10.002.

16. Pruszewicz A, Obrębowski A, Wiskirska-Woźnica B, Wojnowski W. [Complex voice assessment - Polish version of the Voice Handicap Index (VHI)]. Otolaryngol Pol. 2004;58:547-49. Polish.

17. Sonninen A. The external frame function in the control of pitch in the human voice. Ann N Y Acad Sci. 1968;155:6890, https://doi.org/10.1111/j.1749-6632.1968.tb56750.x.
18. Mathieson L. Greene and Mathieson's the voice and its disorders. 6th ed. London: Whurr; 2001. p. 314-5.

19. Van Houtte E, van Lierde K, Claeys S. Pathophysiology and treatment of muscle tension dysphonia: A review of the current knowledge. J Voice. 2011;25(2):202-7, https://doi. org/10.1016/j.jvoice.2009.10.009.

20. Aronson AE. Clinical voice disorders. 3rd ed. New York: Georg Thieme; 1990.

21. Elliot N, Sundberg J, Gramming P. Physiological aspects of a vocal exercise. J Voice. 1997;11:171-7, https://doi. org/10.1016/S0892-1997(97)80075-6.

22. Roy N, Ford CN, Bless DM. Muscle tension dysphonia and spasmodic dysphonia: The role of manual laryngeal tension reduction in diagnosis and management. Ann Otol Rhinol Laryngol. 1996;105(11):851-6, https://doi.org/10.1177/000 348949610501102.

23. Malki KH, Mesallam TA, Farahat M, Bukhari A, Murry T. Validation and cultural modification of Arabic voice handicap index. Eur Arch Otorhinolaryngol. 2010;267:174351, https://doi.org/10.1007/s00405-010-1296-x.

24. Smits R, Marres H, de Jong F. The relation of vocal fold lesions and voice quality to voice handicap and psychosomatic well-being. J Voice. 2012;26(4):466-70, https://doi. org/10.1016/j.jvoice.2011.04.005.

25. Redenbaugh MA, Reich AR. Surface EMG and related measures in normal and vocally hyperfunctional speakers. J Speech Hear Disord. 1989;54:68-73, https://doi.org/ 10.1044/jshd.5401.68.

26. Dejonckere PH, Bradley P, Clemente P, Cornut G, CrevierBuchman L, Fredrich G, et al. A basic protocol for functional assessment of voice pathology, especially for investigating the efficacy of (phonosurgical) treatments and evaluating new assessment techniques. Guideline elaborated by the Committee on Phoniatrics of the European Laryngological Society (ELS). Rev Laryngol Otol Rhinol. 2001;258:77-82, https://doi.org/10.1007/s004050000299.

27. Sukanen O, Sihvo M, Rorarius E, Lehtihalmes M, Autio V, Kleemola L. Voice Activity and Participation Profile (VAPP) in assessing the effects of voice disorders on patients' quality of life: Validity and reliability of the Finnish version of VAPP. Logoped Phoniatr Vocol. 2007;32:3-8, https://doi.org/10.1080/14015430600784386.

28. Schindler A, Ottaviani F, Mozzanica F, Bachmann C, Favero E, Schettino I, et al. Cross-cultural adaptation and validation of the Voice Handicap Index into Italian. J Voice. 2010;24(6):708-14, https://doi.org/10.1016/ j.jvoice.2009.05.006.

29. Rubin JS, Lieberman J, Harris TM. Laryngeal manipulation. Otolaryngol Clin North Am. 2000;33(5):1017-34, https://doi.org/10.1016/S0030-6665(05)70261-9. 
30. Houtte E, van Lierde K, Claeys S. Pathophysiology and treatment of muscle tension dysphonia: A review of the current knowledge. J Voice. 2011;25(2):202-7, https://doi. org/10.1016/j.jvoice.2009.10.009.

This work is available in Open Access model and licensed under a Creative Commons Attribution-NonCommercial 3.0 Poland License / Ten utwór jest dostępny w modelu open access na licencji Creative Commons Uznanie autorstwa - Użycie niekomercyjne 3.0 Polska - http://creativecommons.org/ licenses/by-nc/3.0/pl/deed.en. 